\title{
Translation Research of Conjunctions in English-Chinese Literature Based on Parallel Corpus
}

\author{
Linling Zhong \\ The University of Nottingham Ningbo China, Ningbo 315000, China \\ naomi_zll@163.com
}

\begin{abstract}
Parallel corpus is widely used in Translation works and helps scholars achieved a certain degree of effect. However, English and Chinese language have differences which means the translation cannot be completely equal. This paper is based on the English-Chinese Classics Corpus (ECCC) to analyze the translation of conjunction in English-Chinese literary works. A contrastive study method is adopted to investigate the similarities and differences of discourse cohesion and emotion in English-Chinese literary works. The research also aims to illustrate the translation mechanism of English-Chinese conjunctions and the possible influence on the translation.
\end{abstract}

Keywords: parallel corpus, literary works, conjunctions, translation.

\section{Introduction}

Translation corpus research is developing quickly which leads to the emerging of representative research results. (Liao Qiyi 2000:380; Zhang Meifang 2002:54; Wang Kefei 2003:410) Because translation is a process produced by the source text language, scholars must compare not only the characteristics of the source Chinese text and the translated text, but also the relationship between the translated text and the source English text. (Qin Hongwu \& Wang Kefei 2009:131) According to this line of thinking, this paper studies the function, usage, distribution of conjunctions in English novels, Chinese novels, translated English novels and translated Chinese novels with the help of self-build English-Chinese Classics Corpus. Quantitative discourse analysis and comparison are used to study the similarities and differences of the conjunctions in order to explore the influence on the translation.

\section{Parallel Corpus}

Corpus consists of a great quantity of information and it is existing in language materials. It is fundamental language resources based on computer and can be used to study, analysis language. A Parallel Corpus consisting of the original text and the corresponding translated text. Nowadays, Parallel Corpus becomes an important methodology for language research and teaching because of its unique function. Parallel Corpus, which belongs to Bilingual Corpus, has much more language examples, wider register, stronger effectiveness and richer contexts compared to traditional dictionaries. It can be widely used for translation study, bilingual comparison, language teaching and self-learning. Besides, it provides real data bank for scholars to do quantitive research, which is meaningful. The quantitive research based on the Parallel Copus, which is focusing on controlling language variation, is according to William Wiersma, and it provides effective guidance for analyzing and comparing language.

\section{English-Chinese Conjunctions}

Syntactic structure between English language and Chinese language is different. Sentence structure in English focuses on formality and is relatively more complicated. This kind of structure relies on conjunctions. Sentence structure in Chinese focuses on significance, and rarely uses conjunctions between clause and clause. Conjunction is a more virtual part in sentences than adverb and preposition in sentences. Conjunction connects words, phrases, clauses, sentences, sentence groups and paragraphs without modification and it does not act as a constituent of a sentence. 
Conjunctions can be divided into varies categories and there is no clear benchmark. There are roughly two categories: coordinating conjunction and subordinating conjunction.

\subsection{Usage of English-Chinese Conjunctions in English Novels}

Conjunction in English novels has a regular pattern: coordinating conjunction is used more frequently than subordinating conjunction. To be more specific, coordinating conjunction such as "and", "or" has higher frequency of use than other coordinating conjunctions, such as adversative conjunction "but". For example, in Pride and Prejudice, adversative conjunctions occupy $11.37 \%$ and in Uncle Tom's Cabin is 7.35\%. In subordinating conjunction, "if", "because", "unless" and "that" have a huge range of usage. For instance, in Jane Eyre, "that" accounts for $7.13 \%$ of all conjunctions and in Matin Eden, it goes up to 13.46\%, which is the highest in English-Chinese Classics Corpus. In Translated literary works, it is obvious that the amount of conjunctions declines and the conjunctions in translated text in every one hundred sentences are quite similar with the conjunctions in Chinese original novels.

Table 1. The Law of Joint Words in English Novels

\begin{tabular}{|c|c|c|c|}
\hline Author & $\begin{array}{c}\text { Literary } \\
\text { Work }\end{array}$ & $\begin{array}{c}\text { Conjunctions in Source Text } \\
\text { in Every One Hundred } \\
\text { Sentences }\end{array}$ & $\begin{array}{c}\text { Conjunctions in Translated Text } \\
\text { in Every One Hundred } \\
\text { Sentences }\end{array}$ \\
\hline $\begin{array}{c}\text { Charlotte } \\
\text { Brontë }\end{array}$ & Jane Eyre & 137.12 & 48.95 \\
\hline Jane Austen & $\begin{array}{c}\text { Pride and } \\
\text { Prejudice }\end{array}$ & 152.92 & 59.09 \\
\hline $\begin{array}{c}\text { Harriet } \\
\text { Beecher } \\
\text { Stowe }\end{array}$ & $\begin{array}{c}\text { Uncle Tom's } \\
\text { Cabin }\end{array}$ & 147.83 & 47.59 \\
\hline $\begin{array}{c}\text { John Griffith } \\
\text { London }\end{array}$ & Matin Eden & 117.96 & 39.86 \\
\hline
\end{tabular}

\subsection{Usage of English-Chinese Conjunctions in Chinese Novels}

Chinese novels written by Wang Meng, Lao She and etcetera have quite quantity of conjunctions in every one hundred sentences, especially Lao she. In particular, conjunctions appears every two sentences in Wu Yan de Shu written by Wang Meng. The low frequency use of conjunctions is in Wang Zengqi's and Su Tong's novels. There is only one conjunction in every five sentences. Actually, Wang Meng and Lao She are good at English and they all take part in translation works, which means they are affected by foreign language. Thus, their literary works are westernized and have more conjunctions.

Table 2. Take Lao She, Wang Meng, etc. as an example

\begin{tabular}{|c|c|c|c|}
\hline Author & Literary Work & Conjunctions & $\begin{array}{c}\text { Conjunctions in Source Text in Every One } \\
\text { Hundred Sentences }\end{array}$ \\
\hline $\begin{array}{c}\text { Wang } \\
\text { Meng }\end{array}$ & Wu Yan de Shu & 120 & 54.3 \\
\hline Lao She & $\begin{array}{c}\text { Luo Tuo } \\
\text { Xiangzi }\end{array}$ & 2315 & 45.35 \\
\hline $\begin{array}{c}\text { Wang } \\
\text { Zengqi }\end{array}$ & Shou Jie & 102 & 18.78 \\
\hline Su Tong & $\begin{array}{c}\text { Qi Qie Cheng } \\
\text { Qun }\end{array}$ & 259 & 21.56 \\
\hline
\end{tabular}




\subsection{Translation of English-Chinese Conjunctions}

In translation theories, there are two kind of representative thinking conflicting with each other. One emphasizes that translation must be faithful to the spirt in source text and parataxis, and the other is overfastidious in wording and the translation focuses on hypotaxis. The former one criticizes that the latter one is picky and soustraduire, whereas the latter one thinks that the former one is surtraduire.(Yu Zhongxian, 2000:123) Comparing the translated English literary works with the Chinese original novels, the frequency of the conjunctions are close, which means translators pay more attention to parataxis when translating literary works and the language in translated text would be close to the target language.

\section{Conclusion}

Conjunctions reflects the logical relationship between sentences and sentences, paragraph and paragraph. It is important for translators to analyze grammar, logic and grasp the author's thinking and understand the source text correctly. Further study of conjunctions in Parallel Corpus can help translation and make translation more reasonable. This paper needs to do more research to analyze deeply.

\section{References}

[1]. Liao Qiyi. (2000). Corpus and Translation Studies. [J] Foreign Language Teaching and Research.

[2]. Qin Hongwu\& Wang Kefei. (2009). Language Feature Analysis of English-Chinese Translation Based on Corresponding Corpus. [J] Foreign Language Teaching and Research.

[3]. Wang Kefei. (2003). Correspondence Study of English-Chinese and Chinese-English Sentences Based on Corpus. [J] Foreign Language Teaching and Research.

[4]. Yu Zhongxian. (2000). Left Bank Literature. [M] China Film Press.

[5]. Zhang Meifang. (2002). Investigating Translator's style Based on Corpus. [J] Journal of PLA University of Foreign Languages.

[6]. Zhang Meifang. (2006). Contemporary Cognitive Psychology. [M] Shanghai Educational Publishing House. 